\title{
Introduction - Porous Metals: From Nano to Macro - CORRIGENDUM
}

Nihad Dukhan, Yu-chen Karen Chen-Wiegart, Ashley Paz y Puente, Dinc Erdeniz, David C. Dunand

DOI: https://doi.org/10.1557/jmr.2020.282 solidification rates and post-casting heat treatment J. Mater. Res., 35(19), 2587-2596 (2020).

The volume/issue for reference 25 of this article ${ }^{1}$ was published incorrectly; the citation should appear as follows:

25. P. Lloreda-Jurado, S. Wilke, K. Scotti, A. Paúl-Escolano, D. Dunand and R. Sepúlveda: Structure-processing relationships of freeze-cast iron foams fabricated with various

\section{Reference}

1. N. Dukhan, Y. Chen-Wiegart, A. Puente, D. Erdeniz and D. Dunand: Introduction - Porous Metals: From Nano to Macro. J. Mater. Res., 35(19), 2529-2534 (2020). 